\title{
CASE OF ANTHRAX IN AN OSTRICH.
}

By WM. Robertson, M.R.C.V.S., Government Veterinary Bacteriologist, Grahamstown, South Africa.

IT has been generally supposed that the ostrich, in common with other birds, possesses an immunity (under natural conditions) to anthrax, but this would appear not to be the case.

The diseases of the ostrich under domestication are being studied at this laboratory, and the subject of this note was a full-grown hen bird (one of seven) in a wire-fenced kraal.

These seven birds had been under observation for seven weeks;

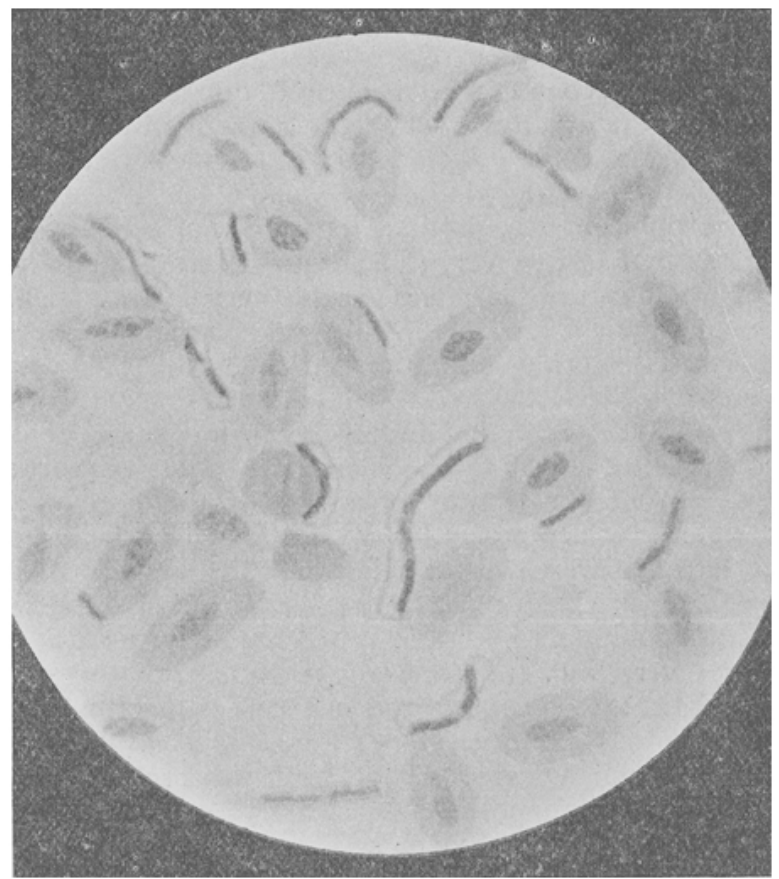

Film of ostrich blood, showing anthrax lacilli (from a photograpls marle by Mr A. J. Sheather, , 1000).

the kraal was a clean one, and no case of anthrax has occurred in the station since its commencement fourteen years ago. The birds were noticed to feed well in the morning, the ration being mealics and prickly pear leaves, and they were seen by the manager at midday. At 2.30 P.M. one was noticed to be lying on the ground quite dead, with the head and neck twisted back over the body.

A post-morten examination was made at once. The blood was quite fluid, and the muscles twitched under the knife. The intestinal tract was almost empty (the crop being full), and congested from end to end. The mucous membrane was much congested and covered with minute areas of hæmorrhage, and the lumen of the intestine 
contained a quantity of clear mucus streaked with blood. The spleen was much enlarged, soft, and dark in colour.

Microscopic examination of the blood (see accompanying figure) showed numerous bacilli, identical morphologically and in staining characteristic with those of anthrax, and a smear which was sent to Sir John M'Fadyean enabled him to corroborate the diagnosis.

\section{Abstrats and genourt.}

\section{CEREBRAL TUBERGULOSIS IN A HEIFER.}

TUEERCuLosis of the nervous centres is fairly frequent in the ox tribe, and is the cause of many of the chronic or sub-acute nervous disorders seen in these animals.

Tuberculous lesions may affect either the meninges or the nerve substance, but whatever their situation they produce a complex of symptoms common to changes in either, so that it is very difficult to determıne clinically whether the lesions chiefly affect the meninges or the nerve substance. Clinically, therefore, the author only recognises tuberculous meningo-encephalitis or meningo-myelitis. The former condition produces the classic symptoms of "immobility."

Observation seems to show that in tuberculous lesions of the nervous cen res the commonest lccalisation is in the anterior portions of the brain, in the depths of the frontal lobes and of the temporal lobes. In the heifer, to which the article under review referred, the lesions were so situated. The latter, a two-years-old heifer of native breed, had been sent to the veterinary college as affected with "turn-sick," and had been admitted to Professor Liénaux's clinique.

The animal was very thin, and showed symptoms pointing almost exclusively to disease of the locomotor and nervous apparatus. It appeared extremely depressed and exhibited general symptoms of "immobility." It assumed the most peculiar positions; the back was arched and all four legs were placed under the body; the front legs were crossed as in cases of immobility in the horse. The coronet seemed slightly sensitive to pressure, but the animal did not resent the introduction of a finger into its ear, and failed to respond, or responded very slightly, to other stimuli. In the stall it hung back from the manger, and kept its head constantly turned towards the left. It did not take either food or drink when off red, but when its head was pushed into a pail containing water or liquid food it made a few swallowing movements, suddenly stopped, withdrew its head, and did not again attempt to drink unless its head were again plunged into the liquid. When at liberty it only moved forward if strongly urged, and then made "circus movements" to the left. In addition, there was a slight discharge from the nose, respiration was slow and superficial, and the vesicular murmur was absent.

Although the symptoms pointed to change in the chief nervous centres, they were insufficient precisely to indicate the nature of the morbid process, inasmuch as they were those common to tuberculous meningo-encephalitis and cerebral coenurosis, and resembled the symptons shown in other lesions 